\title{
The Epistemic and Informational Requirements of Utilitarianism
}

\author{
HUGH BREAKEY \\ University of Queensland
}

\begin{abstract}
A recurring objection confronting utilitarianism is that its dictates require information that lies beyond the bounds of human epistemic wherewithal. Utilitarians require reliable knowledge of the social consequences of various policies, and of people's preferences and utilities. Agreeing partly with the sceptics, I concur that the general rules of thumb offered by social science do not provide sufficient justification for the utilitarian legislator to rationally recommend a particular political regime, such as liberalism. Actual data about human preference-structures and utilities is required to bridge this evidentiary gap. I offer two arguments to support the availability of such information. First, I contend that ordinary human beings have a clear method of epistemic access to reliable information about commensurable preference-structures. Second, in an attempt to shift the onus of philosophic argument, I show that the utilitarian legislator's requirements do not differ in kind from those implicitly called upon by the sceptical deontic liberal.
\end{abstract}

Almost since its birth, utilitarianism has been subject to a quite unique objection. It is charged that the dictates of utilitarianism - as both a personal and public morality - are impossible to follow because they require information that lies beyond the bounds of the human mind.

In terms of utilitarianism as a public (or political) morality, which will be my exclusive focus in this article, a wide swath of arguments was immediately brought to bear against the idealistic hopes of the first utilitarians that simple application of hedonic calculi could serve as a determinate and demonstrable basis for all legislation and political policy. ${ }^{1}$ The first such challenges to utilitarianism were perhaps a little crude, and one can sense the frustration of John Stuart Mill when he retorted that, 'there is no difficulty in proving any ethical standard whatever to work ill if we suppose universal idiocy to be conjoined with it'. ${ }^{2}$

Over time, however, as more realistic and refined accounts of utilitarianism were offered, the objections themselves became increasingly more sophisticated, drawing on decision theory, analyses of market structures, and epistemological constraints to show that these accounts avoided justifying crucial steps, or conceded too much. An implication that can be drawn from these considerations is that

1 Mary Warnock, 'Introduction', Utilitarianism and on Liberty, ed. Mary Warnock (Oxford, 2003), pp. 1-16.

2 John Stuart Mill, 'On Liberty', ed. Elizabeth Rapaport (Cambridge, 2003), p. 24.

(C) 2009 Cambridge University Press

doi:10.1017/S0953820808003373
Utilitas Vol. 21, No. 1, March 2009

Printed in the United Kingdom 
utilitarianism cannot justify an overall type of political system. In particular, utilitarianism cannot justify liberalism. By 'liberalism' I refer to the collection of various key features of the liberal polities of the western world, such as their adherence to civil rights, democracy, rule of law and their market-based economies.

I will argue that upon inquiring into the precise epistemic requirements of utilitarianism, we have good reason to believe that these requirements can be met - at least to the level required to allow the justification of an overall polity.

My argument proceeds as follows: after considering some relevant decision-theoretic issues in $\S 1$, in $\S 2$ I will introduce some very general social science postulates concerning interactions between and within agents in terms of their behaviour, beliefs, resources and preferences. The key question then arises: whether extrapolation from these types of postulates will provide enough information for the utilitarian to immediately and without further ado justify a particular polity, such as liberalism. I will sketch three ways in which such a justification might be envisaged to take place, and conclude in each case that the utilitarian requires more information than that encapsulated within the postulates. This negative result, however, will be useful in elucidating the type and amount of information the utilitarian requires in order to build upon such social science. The utilitarian must be able to make Three Requisite Claims, each of which involves knowledge about other people's preferences and overall utilities.

In $\S 3$ then, I will give two arguments suggesting that the required type and amount of information is available. The first argument will provide a conceptual epistemic account of how this sort of information may be accessed. The second argument will show that the informational requirements necessary for answering the Requisite Claims are not, in fact, different in kind from those necessary for the implementation of any other non-anarchic polity, and therefore that - while it is possible that these concerns cannot be met - there is a prima facie tension for any theorist who wishes on the one hand to contend that utilitarianism has particular epistemic or informational problems, but on the other wishes to put forward in its place any non-anarchic polity.

I conclude that a utilitarian justification of liberalism is possible given the practical epistemic constraints of human beings. Ultimately I won't show that utilitarianism justifies liberalism - rather I will argue that there is no epistemic impediment to its doing so.

\section{RATIONALITY AND THE ACTION HORIZON}

Before proceeding any further, it is worth clarifying some terminology. A cardinal preference that an individual has is the propositional content 
of a preference combined with the cardinal measure of the intensity with which it is preferred. An individual's preference-structure is that individual's entire set of cardinal preferences. The individual's utility combines their preference-structure with the objective measurement of the degree to which each of those preferences is fulfilled; an individual thus has a higher utility the closer he is to the maximum given the available social conditions. Overall utility is created by the addition of all such individual utilities across a given population. I will simply assume that people do have largely coherent preference-structures ${ }^{3}$ and that different states of the world can fulfil them to greater or lesser degrees, meaning they also have utilities. In $\S 3$ I will argue that preference-structures and utilities are knowable by others and that they are intersubjectively comparable.

Utilitarianism mandates that individuals morally ought to maximize expected overall utility, so defined. It is worth discussing a few decisiontheoretic issues which bear directly on the levels of information required to engage in such an endeavour. It is a commonplace in decision theory to distinguish between 'rational' decisions (which maximize expected utility given the estimated probabilities of each outcome) and 'right' ones (the decisions that, as things turned out, caused the best or equal best outcome). ${ }^{4}$ In complex real-world situations it is rarely the case that the rational choice is the right one. There is almost always something that would have been done differently if perfect foreknowledge had been possible. It is occasionally argued as if the business of the utilitarian is to make the right decision, ${ }^{5}$ and that failure to do so constitutes a 'missing of opportunity' ${ }^{6}$ that is in some sense analogous to the (all-or-nothing) failure to reach a destination. ${ }^{7}$ This is simply a mistake. The business of the utilitarian is to maximize expected utility - to make rational decisions. ${ }^{8}$ This procedure need not require - nor even correlate with - the making of right decisions.

${ }^{3}$ This is obviously both an important and contentious assumption. Doing any sort of justice to a discussion of it, however, would take me too far from my course.

${ }^{4}$ M. D. Resnik, Choices: An Introduction to Decision Theory (Minneapolis, 1987), p. 13.

${ }^{5} \mathrm{I}$ am using - and will continue to use - the words 'right' and 'rational' in this artificial decision-theoretic sense because I wish to emphasize that complaints against the utilitarian for not getting it 'right' are as ineffectual as claims against an individual non-tuistic agent that their rational action did not turn out to be 'right'. However, I am sacrificing clarity for consistency here - both 'rational' and 'right' obviously have other connotations.

6 Jon Elster, Nuts and Bolts for the Social Sciences (Cambridge, 1989), p. 170.

7 Gerald F. Gaus, 'Why All Welfare States (Including Laissez-Faire Ones) Are Unreasonable', Social Philosophy and Policy 15.2 (1998), p. 25.

${ }^{8}$ Frank Jackson, 'Decision-Theoretic Consequentialism and the Nearest and Dearest Objection', Ethics 101. 3 (1991), pp. 461-82. 
In order to make rational decisions, the utilitarian must be able to make justifiable claims about the estimated utilities and probabilities of the available strategies. If she cannot make any such claims about at least one of her options, the utilitarian faces what in decision-theoretic terms is known as a 'decision under ignorance', where maximization is impossible. ${ }^{9}$ Note however, what an extraordinarily strong claim it is to say that we can make no claims about the probability-of-success or utility of some option. For example, to say that a utilitarian in considering two crime-prevention strategies (say, 'increased sentences' versus 'more job opportunities for the poor') is in a decision under ignorance is just to say that they can make no justified probability or utility estimates regarding at least one of the strategies. This would have the direct corollary that the utilitarian could not claim that this strategy was likely to be better than any other strategy which we may discard out of hand - such as rewarding criminals with cash and slaves.

In decision theory, a decision under ignorance is typically contrasted with a 'decision under risk', this latter being a decision where we can indeed make justified probability and utility imputations. While it is worth recognizing how strong a claim it is to say that we are facing a decision under ignorance, it must also be admitted that a decision under risk - as conceived in strict decision theoretic terms - is equally as extraordinary a claim. For it requires having an exact probability number or utility level to feed into utility calculations and decision tables. In fact, however, the vast majority of imputations we are likely to make are vague. Even those utility imputations of which we are most confident are likely to be (at some given decimal point) no more than estimates over a given interval. Often, the same reasons we have for imputing the interval are reasons for having an idea about probability distribution across that interval, but this does not ultimately dissolve the problem of vagueness, for the indeterminacy simply recurs on this higher level of probability distribution across the interval.

In the real world then, vagueness will be an inevitable part of all decisions, and we will often lie in an unenviable position somewhere between pure ignorance and risk. Such vagueness need not render impossible decision-making on utilitarian bases any more than it does so in everyday personal realms. The crucial issue is the extent of the vagueness (the wideness of the imputed intervals), for this determines our capacity to individuate one correct strategy. ${ }^{10}$ Legislators may often

9 That is, it is not possible unless one, as it were, artificially creates the probabilities, for instance by appeal to the Principle of Insufficient Reason. However, there are good reasons for wanting to avoid any such move. See Resnik, Choices, p. 37.

10 The problems here are exactly those which confront individual (as distinct from social/utilitarian) decision theory. There is a burgeoning literature on the use of such 
be faced with a group of policies which, given the vagueness associated with their respective utilities and probabilities of success, are equally ranked by utilitarianism. While the legislators may not be able to choose which policy is best within this group, they may well be able to confidently state that all these policies are clearly superior to some other group of policies, which is in turn superior to another group, and so on. In such cases utilitarianism is capable of limiting the options, but not of determinately selecting amongst them. ${ }^{11}$

This requirement of avoiding decisions under ignorance has another specific area of relevance. It is occasionally claimed that a key problem for utilitarianism is not so much centred on whether an agent can achieve a particular goal, but whether she can reasonably assume that the unnoticed effects of her action - effects peripheral to the particular goal at hand - will not have any major deleterious consequences. If we cannot make probability estimates within a workable degree of vagueness about the likelihood of such consequences then all utilitarian decisions are made under ignorance. On the other hand, if we have justified reasons to believe that peripheral and unnoticed side-effects will not significantly impact upon expected utility, then the immediate benefits directly before us become rationally decisive.

There are several reasons for thinking that agents have strong justifications for imputing very small probabilities to large-scale consequences arising from the unnoticed and peripheral effects of their action. Let's introduce some terminology here and say that an effect falls outside the action horizon when an agent justifiably neglects it or considers it and then justifiably puts it aside - in her assessment of consequences and expected utility.

The first reason that some events fall outside the action horizon is simply that (subject to two forthcoming caveats) small changes do not normally make big differences to future events. Prosaically, kingdoms may indeed be lost for want of a nail, but set against the backdrop of the amount of nails wanted on an everyday basis, it is atypical for singlenail shortages to collapse major dynasties. Notwithstanding this, there are two circumstances where we might think this general rule of thumb is liable to prove false.

First, while unnoticed and peripheral effects may, in and of themselves, have little consequence, it is nevertheless possible that these effects, in concert with similar effects from millions of others' similar actions, can ultimately have significant consequences - particularly

utility intervals as are created by this vagueness, e.g. Prasanta S. Bandyopadhayay, 'In Search of a Pointless Decision Principle' (paper presented at the PSA: Proceedings of the Biennial Meeting of the Philosophy of Science Association, 1994).

11 Robert E. Goodin, Utilitarianism as a Public Philosophy (New York, 1995). p. 21. 
in environmental contexts. The actual contribution of any one act to an environmental disaster like global warming or ozone depletion is extremely small, but a tiny contribution to a catastrophe may still carry non-trivial disutility. This realization may give us pause in our utility-estimations of peripheral effects in those cases where we surmise that these effects are being replicated on a massive scale by others. Even in such cases, however, it is still the norm only to give serious weight to such consequences when we have specific evidence of deleterious consequence. There are innumerable 'similar effects' instantiated by humans every day which we have no reason to believe will ever create significant environmental problems.

As to the second circumstance: in chaotic systems infinitesimal differences in initial positions can (and in many cases must) give rise to vast discrepancies later. 'Chaotic' here is used as a mathematical term of art - the chaos of politics or war, for instance, need not be chaotic in this strict sense. There are undoubtedly a variety of chaotic systems impacted upon by human action - most obviously, the weather. Whether or not I move to save a child from a falling bookcase may, if circumstances in the atmosphere are structured appropriately, cause a movement of air that will eventually (perhaps in thousands of years) be a decisive causal component in the formation of a devastating tornado. However, while chaotic systems constitute potential exceptions to this first rule of thumb, the following several considerations can be salient even in chaotic situations.

A second reason we have for imputing minimal changes to expected utility from small effects is that we might have reason to believe these effects are simply not constituted in such a way as to alter the probabilities of future events. Whether or not one pauses briefly before rolling a pair of dice may alter the result from what it would otherwise have actually been, but in so doing one does not change the probability of any particular numerical result, and hence does not change in any way the expected utility of any wager whose outcome is contingent upon the result.

A third reason for placing effects outside the action horizon is that while we may often have difficulty imputing the probability of a particular occurrence, we may also have good reason to think it will be similar to a countervailing occurrence. I may not know the chances of whether a given child will grow up to be a murderer - but if I am faced with the choice of saving one of two drowning children it is enough for me to know their chances of being a murderer are roughly equal for each person, given that they are both drawn from the same human stock. ${ }^{12}$

12 The appeal to countervailing considerations (or 'balancing out') is a useful device in utilitarian calculations - but it can be blithely overused. As noted in Robert E. Goodin, Political Theory and Public Policy (Chicago, 1982), p. 166. 
Fourth, we often justifiably assign lower probabilities to events occurring far into the future. The obvious reason for this is that myriad events, small and large, may interrupt the causal concatenation that leads to the specific hypothesized event. But there is a particular reason we assign low probabilities to large-scale deleterious consequences occurring far in the future - namely that we ourselves (and other moral agents) may have myriad opportunities in the intervening time to stop the dominoes falling, or at least to ameliorate the problems caused by an inevitable event. Every act is not the last word on a subject.

These several reasons all suggest that unnoticed effects typically do not impact greatly on expected utility. There is a more general reason for accepting this claim. Simply, if unnoticed effects of some type did tend to have large-scale consequences then we would begin to take notice of these effects. Certain effects acquire the status of unnoticed effects precisely because, over time and through noticing the effects of our actions on others and the effects of other's actions on us, we have learned to notice those effects which tended to have major consequences and ignore those effects which did not. This general confidence we have in the lack of major consequences from unnoticed effects can be further supported if we put in place systems that allow feedback on our actions, such that other people are able to voice their opinion on whether some action is having unwanted effects in an area orthogonal to our particular focus but relevant to their particular projects.

The claim here is not that unnoticed, peripheral and seemingly small effects do not ever have terrible consequences. Rather, the claim is merely that, absent specific evidence to the contrary, agents are strongly justified in believing such effects will negligibly impact on an action's expected utility. It is this reasoning which justifies (in some circumstances at least) the utilitarian acting for some immediate utilitarian gain and believing that all other things will be - in the main - equal. It is worth noting that symmetrical concerns occur in purely personal decision-making. In assessing the consequences of a business venture or personal relationship to one's life prospects, if an individual is to make a justified decision under risk, there must be some point at which he can reasonably conclude that further consequences of exfoliating causal chains need not be considered in his calculations.

One other important corollary of the action horizon is the lessening of factors to which a utilitarian agent must pay heed in her calculations a wide variety of imaginative speculations about whether people are liable to commit murders or cure cancers falls beyond the action horizon. ${ }^{13}$ The ability to justifiably ignore such speculations

${ }^{13}$ See Gerald F. Gaus, Social Philosophy, ed. James H Fetzer (New York, 1999), pp. 64-6, for an outline of what utility-calculi would look like without any access to the action-horizon. 
reduces the utilitarian's information-gathering and computational requirements.

To summarize to this point: utilitarianism requires making decisions under risk within workable bounds of vagueness. This in turn requires that probabilities and utilities may be justifiably estimated, and that the action horizon be utilizable to know which effects are unlikely to have significant impact on expected utility.

\section{THE POSTULATES AND THE REQUISITE CLAIMS}

The next issue that confronts us is whether - from the menagerie of diverse rules of thumb (the 'toolbox of mechanisms' as Jon Elster puts it ${ }^{14}$ ) that can be distilled from social science - the utilitarian is able to justifiably make a decision under risk in favour of an overall political regime such as liberalism. To answer this question, let us review a laundry list of the sort of social science postulates to which the utilitarian may refer.

1. The indirect postulate: it is easier to follow a rule than it is to instantiate a goal. It takes less ratiocinating power to work out if current circumstances fall under the ambit of a rule than it does to calculate what the effects of any given action will be particularly if the desired goal is not immanent. ${ }^{15}$ Certain other aspects of rule-following are worth noting - for instance that rules are, compared to goal-directed action-strategies, easier to remember, easier to communicate and easier to recognize in others' behaviour. ${ }^{16}$ Let's also note that agents interacting on the basis of pre-established rules allows for the possibility of coordinated outcomes - leaving it an open question whether in any case a coordinated outcome is a useful addition to their set of alternatives. ${ }^{17}$

2. The liberal postulate: in most circumstances, the individual best placed to fulfil a particular preference is the preferring agent himself. People have more intimate and comprehensive knowledge of their own goals and, perhaps most importantly, are intrinsically motivated to fulfil their own goals. Furthermore, they will often have comparatively greater opportunities for fulfilling their goals, given that such goals usually involve the preferring agent himself in manifold ways - perhaps the

14 Elster, Nuts and Bolts, p. 168.

15 F. A. Hayek, The Mirage of Social Justice, Law, Legislation and Liberty (London, 1982), p. 8.

16 Goodin, Utilitarianism as a Public Philosophy, p. 17.

17 See Russell Hardin, 'The Utilitarian Logic of Liberalism', Ethics 97 (1986), pp. 47-74, for an attempt to close this question. 
preferred state of affairs has a natural physical propinquity to the agent, or the agent is a part of the state of affairs, or the agent wishes to personally cause the state of affairs, or the agent wishes to personally know if the preferred state of affairs inheres. ${ }^{18}$ Finally, personal goals have certain other features such as being time-discounted and restricted in scope - which makes them easier to fulfil than more other-regarding (social) ones. ${ }^{19}$

The liberal postulate militates in favour of respecting the different decisions made by agents to invest their time and energy in acquiring disparate types of resources. ${ }^{20}$ Each person's preference-structure will have idiosyncratic requirements for different types of resources: economic resources, free time, levels of health, fitness and even beauty, standards of security and stability, degree and nature of education, the extent and content of one's social sphere or political influence, and so forth. If circumstances allow, agents acting over time may be able to focus on the accumulation of resources germane to their own particularized requirements. If so, then any exogenic redistribution (say, an egalitarian redistribution) of any of these aforementioned goods may well constitute taking a good from someone whose preferences specifically require it, and providing it to someone whose use and appreciation of it is much more limited, given her own preference-structure.

3. The free-market postulate: the typical response of agents to an environment where property and exchange are protected is to deliberately find a method of fulfilling others' needs and to use this capacity to generate resource for themselves. This is the invisible hand of Adam Smith at work, explaining how the free market subtly hitches any agent's betterment of her own situation with the bettering of others' situations. ${ }^{21}$ F. A. Hayek added to this thesis the efficient use the market makes of decentralized information. Needs are fulfilled, not by the deliberate connivance of any centralized organization, but by the intuitive entrepreneurial skills of all humans, in exploiting their particular position and knowledge to their own, and subsequently other people's, benefit. ${ }^{22}$ Note that the

18 Henry Sidgewick, The Methods of Ethics (London, 1907), p. 431.

19 Gaus, 'Welfare States', p. 20.

20 Mill, 'On Liberty', pp. 74, 107.

21 Adam Smith, An Inquiry into the Nature and Causes of the Wealth of Nations, ed. Edwin Cannan, vol. 1 (London, 1950), pp. 475-7.

${ }^{22}$ F. A. Hayek, 'The Use of Knowledge in Society', The American Economic Review 35. 4 (1945), pp. 519-30, esp. 521. 
free-market postulate is only advancing the above broad claims about behavioural responses; I am not intending any of the much stronger contentions that, for example, the unfettered free market most efficiently distributes scarce resources, or maximally makes use of all available information. This postulate is not theoretical - it simply follows from observations of the relative productivities of command economies compared to the much freer markets we observe throughout the western world and elsewhere.

4. The punitive postulate: agents will typically act to avoid imprisonment and monetary fines. Given that agents are motivated to fulfil their preferences and that the best agent for the fulfilling of a preference is typically the preferring agent herself (the liberal postulate), it follows that an agent will ordinarily be motivated to avoid the curtailment of her free action, or a diminishment in her overall resource.

5. The egalitarian postulate: humans fulfil their preferences by applying resource with diminishing marginal returns. ${ }^{23}$ (This is just to say that with each additional quantum of resource invested to a particular person, we can expect a lower return of utility-increase than we procured with the last quantum invested with that person.) If we know nothing further about which particular agents have the more (or less) efficient resource-to-utility conversion functions, then a totally egalitarian distribution must be the rational choice - i.e. the option which will maximize expected utility. (For a full explication of this claim, see the Appendix.) It is worth distinguishing this claim from a perhaps more popular notion of the egalitarian claim, viz. 'given diminishing marginal returns, and an assumption that people's abilities to transfer resources into utility are roughly even, then an egalitarian distribution will be (pro tanto) optimal.' The egalitarian postulate above replaces the ontological assumption in this latter rendition with an epistemological standpoint; instead of presuming people have quite similar resource-toutility conversion functions (which seems false, in any case), let us accept that such functions may well differ greatly from person to person but consider a circumstance in which we don't know which people have the more or less efficient functions. In such a case, the egalitarian postulate states, an equal distribution of resources will maximize expected utility.

${ }^{23}$ Goodin, Utilitarianism as a Public Philosophy, p. 23, also John Elster, 'Local Justice and Interpersonal Comparisons', Interpersonal Comparisons of Well-Being, ed. John Elster and John E. Roemer (Cambridge, 1991), p. 117. 
6. The public-goods postulate: there are certain goals (public goods) which can only be protected or will only be produced by enforcing limitations upon, or exacting contribution from, each member of a group. The logic of collective action shows clearly how individual agents acting rationally can collectively produce outcomes that they would all agree are suboptimal. ${ }^{24}$

I will not argue for the reasonableness of the above postulates. The sceptical arguments confuting the utilitarian project are typically not arrayed against these types of very general and abstracted claims. Rather, they contend the problematic nature of the movement from these sorts of claims to the utilitarian recommendation of specific policies. We will review three attempts by utilitarians to justify this move. In each case I will argue that the justification fails, and that the missing evidence which might justify the conclusion must come in the form of reliable knowledge concerning people's preference-structures and utilities.

The first avenue involves focus on prototypical micro-level actions and interactions, that is, unilateral actions undertaken by a particular agent (such as productive labour), or multilateral interactions between two or more agents (such as trade). The exclusive emphasis here is on the behaviour of, and consequences for, the individual agents involved in these actions/interactions, rather than the policies and outcomes of the politico-economic system as a whole. For instance, the utilitarian might mount a defence of the institution of private property (and ultimately free exchanges of property) on the basis that this allows people to work for (or exchange) goods to improve their own situation over time, and, 'protecting an action that makes someone better off while making no one worse off produces a better state of affairs on the whole'. ${ }^{25}$

An initial problem with this approach is in justifying the 'makes no one worse off' clause. This can be seen as an appeal to what I have in $\S 1$ referred to as the action horizon. The claim is that within the trading dyad we can discern a utility improvement, and we have reasons for believing that consequences arising outside the dyad will not impact significantly on expected utility. The question is: do we indeed have such reasons?

First, it may be that even if some unilateral action on the part of an individual has no significant further consequences on the world, the action itself may constitute a derogation of others' preferences.

${ }^{24}$ Russell Hardin, Collective Action (Baltimore, 1982), pp. 16-37; Gaus, Social Philosophy, pp. 185-90; Garrett Hardin, 'The Tragedy of the Commons', Science 162 (1968), pp. 1243-8.

${ }^{25}$ Hardin, 'The Utilitarian Logic of Liberalism', p. 51. 
This may particularly be the case if these others have other-directed preferences - they are envious, lewd or prudish, say. ${ }^{26}$ Some appeal to preference-knowledge is necessary to show at least that other-directed preferences of this type are not vastly more common and powerful than the type of self-directed preferences that unilateral actions of this ilk are capable of fulfilling.

Presuming this case can be made, this micro-level approach gains in respectability. We can assess various types of unilateral and multilateral action/interaction types in terms of their various capabilities for fulfilling the preferences of the agents involved. Plausible desiderata for making such assessments might include an appeal to input/output efficiency - for each action/interaction type, how many persons and how much time and effort from each does it take to fulfil how many separate preferences? Other desiderata include showing how agents will be aware of the preferences they are intended to fulfil, and be motivated to fulfil them. Broadly liberal action/interaction types excel here because of their elegant answers to questions of knowledge and motivation; agent $\mathrm{X}$ is primarily in the business of fulfilling agent X's preferences, of which, ex hypothesi, $\mathrm{X}$ is cognizant and motivated to fulfil. Yet even here, significant preferencestructure knowledge may be required for determinate answers to the question of the selection and recommendation of optimal strategies: small differences in payoffs, beliefs, iterations, expectations, visibility and neighbourhoods can make surprisingly powerful differences to game-theoretic representation and its subsequent recommendations for what counts as a felicitous action/interaction-type. ${ }^{27}$

Purely on the micro-level of individual actions/interactions, these recommendations may be determinate. The further problem however, is in justifying this focus. The egalitarian and the public-good postulates can both be used to provide cases where the best agent to fulfil a particular preference is not - at least, not primarily - the preferring agent himself. For example, we might find that the overall distributive effect of the free market is radically unegalitarian, and the egalitarian postulate would therefore contend that at least one type of efficiency is being sacrificed by this arrangement. ${ }^{28}$ This inequality might become

${ }_{26}$ Amartya Sen, 'The Impossibility of a Paretian Liberal', Journal of Political Economy 78 (1970), pp. 152-7, esp. 155-6. But see also, Hardin, 'The Utilitarian Logic of Liberalism', p. 72.

${ }^{27}$ Robert E. Goodin, Green Political Theory (Cambridge, 1992), pp. 158-67; Brian Skyrms, The Stag Hunt and the Evolution of the Social Contract (New York, 2004).

28 Alan Haworth, Anti-Libertarianism: Markets, Philosophy and Myth (London, 1994), pp. 12-17. Contrariwise, it is arguable that the most important effects of the free market are its gestalt effects, for instance regarding the free market's effects on the motivation of citizens (such as outlined in the above Free Market Postulate), or in the 
an overriding concern if it threatened to deny to many people the level of choice and control over their lives which the liberal postulate itself recommends. ${ }^{29}$ Alternatively, agents may have shared preferences which require certain public goods - but in a purely laissez-faire free market, such goods may be grossly under-produced and underprotected. If preferences requiring public goods were common, and we have no reason (without any evidence on preference-structures) to presume one way or the other, then our liberal society could be quite suboptimal. ${ }^{30}$ In other words, we have not yet any reason to be more concerned with protecting through personal rights how individuals go about individually fulfilling their individual preferences, than with focusing on collective rights and duties which ensure that groups can go about collectively fulfilling shared preferences. If so, it is not possible to give an account of the prototypical means of preference-fulfilment while remaining entirely silent about the ends (the preferences themselves). ${ }^{31}$ At the very least we will need to know the types of preferences people commonly have - where by 'types' I mean whether they are of the form that can be fulfilled by unilateral and bilateral actions/interactions, or whether they are fulfilled by or require public-goods.

A similar problem ensues for the second avenue. This route focuses on a macro-level of social interaction, and looks at defending a group of primary goods deemed necessary for preference-satisfaction. ${ }^{32}$ The problem is not so much in coming up with such a list. We may fashion a plausible inventory of social desiderata including education, civil liberties, economic equality and rule of law of which we expect that each one taken on its own - given just the relationships between preferences, resources and knowledge outlined in the postulates - would increase utility over some anarchic state of nature. But without appeal to preference-knowledge the utilitarian cannot weigh one desideratum against the other and so cannot meaningfully compromise between them. Yet in all public choice scenarios, including those of choosing an

information contained within the pricing mechanism and the equilibrating tendencies that can spring from this information. L von Mises, 'Economic Calculation in the Socialist Commonwealth', Socialist Economics, ed. Alec Nove and D. M. Nuti (Harmondsworth, 1972), pp. 75-91.

${ }_{29}$ E.g. Thomas Hill Green, 'Lectures on the Principles of Political Obligation', Property: Mainstream and Critical Positions, ed. C. B. Macpherson (Toronto, 1978), p. 101.

30 At various points Hardin acknowledges the need for further knowledge about utilities in order to distinguish which rights (individual or collective) should be upheld: Hardin, 'The Utilitarian Logic of Liberalism', pp. 56, 67-9.

${ }_{31}$ Contra Hayek, The Mirage of Social Justice, p. 3. Hayek is aware of the problems raised by public goods, though his solution involves a quite clear appeal to preferenceknowledge: Hayek, The Mirage of Social Justice, p. 6.

${ }_{32}$ See, broadly, Goodin, Utilitarianism as a Public Philosophy, pp. 20-1. Goodin alludes to the need this avenue has of, at least, some 'rough and ready' knowledge of preferences and utilities. 
overall polity, this necessity of compromising one good for another is ubiquitous. Simplistically, a polity where free-market gains are abjectly compromised for equality might give us various forms of socialism, and a polity where liberty is abnegated by concern for one set of public goods might give us theocracy.

The third avenue widens its focus still further and investigates overall systems and broad social praxes that have worked previously, and acts to uphold them, or even incrementally improve them. Elster distinguishes several problems with the incrementalist approach primarily that the relationship between small-scale, short-term gains and large-scale, long-term gains can be problematized in a variety of ways. ${ }^{33}$ While these concerns are crucial to understand if one is to attempt some form of incrementalism, they are not decisive against the practice per se. They merely show how in certain situations (where localized problems belie long-term, large-scale benefits and allowances cannot be made for this in implementation or assessment) one may 'miss an opportunity'. ${ }^{34}$ More important, as regards our present concerns, is that such approaches implicitly call on a wide swath of preference-information. It is necessary to be able to make assessments of the amount of gain made by one praxis as compared to other available options, to be able to distinguish from myriad other social causal agents which particular praxis is creating the gain, to have some knowledge of how to sustain or correct the praxis in view of changing circumstances, to select a new policy from a potentially infinite set, to have some idea of the problems with tinkering in various ways with the praxis, and what to do when several conflicting praxes each seem to deserve protection. ${ }^{35}$ Even in cases where we wish to keep tinkering to a minimum, and wish only to hold firm to an indigent set of spontaneously evolved praxes which we have reason to believe allow many people to fulfil their preferences, ${ }^{36}$ the utilitarian cannot plead widespread epistemological fallibility in order to avoid considering other approaches. ${ }^{37}$ If we are genuinely ignorant of whether massive gains do or do not lie in other polities then we cannot rationally (or

33 Elster, Nuts and Bolts, pp. 169-70.

34 Elster, Nuts and Bolts, p. 170.

35 Some of these points are argued in Goodin, Political Theory and Public Policy, ch. 2.

36 Such as Hayek would recommend, regarding free markets and systems of justice: Hayek, The Mirage of Social Justice, pp. 4-5.

${ }_{37}$ I leave as an open question whether or not it would be correct to characterize Hayek, given his Humean roots, as a very indirect utilitarian attempting precisely such a justification. See John Gray, Hayek: On Liberty, 3rd edn. (London, 1998), p. 60. Hayek also offered powerful micro-level explanations of why the overall social praxis was likely to be beneficial - which make use of both the first and the third avenues as I have outlined them. 
utilitarianly) recommend liberalism, for any decision to do so is made under ignorance.

I conclude that none of the above avenues are capable of recommending that a utilitarian, on the basis of social science alone, should rationally choose liberalism. Each avenue does constitute a genuine way forward, but each must be supplemented by preferenceknowledge. In order to move from the postulates to a utilitarian justification of liberalism there are Three Requisite Claims we need to be able to make. It is necessary for each of the above avenues to be able to make all these three claims, but I note that each claim has a particular relevance for each of the avenues:

- The Action-Horizon Claim: We know enough about others' preference-structures and utilities that we can estimate what sorts of effects will typically not make much difference to their utilities. (This aids particularly in the justification of the first (micro-level) avenue, as it opens the possibility of saying, 'all other things outside this dyadic exchange will be equal'.)

- The Compromising Claim: We know enough about others' preference-structures and utilities that we can estimate the amount of preference-fulfilment that is coming from not interfering with people's goal-directed pursuits and the amount of preference-fulfilment that comes from protecting a public good or providing for the very poor. (This allows us to estimate within what degree of variance liberal policies should be compromised for egalitarian and public-good initiatives, thus opening the possibility of the second (macro-level) avenue.)

- The Large-Scale Assessment Claim: We know enough about others' preference-structures and utilities that we can estimate whether people in liberal polities have at least as high an average utility as people in other arrangements. (Broadly, this may justify commitment to an indigent set of spontaneously evolved praxes in a particular society, apropos the third (overallassessment) avenue.)

With these Requisite Claims in mind, let us turn to the question of what can be known about the knowledge of others' preferencestructures and utilities.

\section{KNOWLEDGE OF PREFERENCE-STRUCTURES}

The three Requisite Claims each necessitate having knowledge about people's preference-structures and utilities, and being able to compare and aggregate these utilities. First, then, we must consider whether this type of cardinal-preference knowledge is even epistemically 
possible. Second, if it is possible, we must consider whether such information is sufficiently accessible to render the utilitarian calculus workably determinate.

We find out about other people's preference-structures first by looking to our own. ${ }^{38}$ We realize that we are the sorts of entities that have preferences and have them to greater and lesser degrees about all sorts of different things. We also note a link between our preferences and our behaviour, in terms not only of our goal-directed action but also in the way our preferences colour our communications and are expressed and occasionally betrayed in our movements and demeanour. Of course, we also note that other factors besides our preferences create behaviour, including our instincts, habits, subconscious motivations and states of mind (e.g. drunkenness/sleepiness). Similarly, we note that our preferences only create behaviour when conjoined with our beliefs.

These types of realizations are crucial for the next step in the epistemic chain - analogy. ${ }^{39}$ We realize that, seeing that other people have the same causal underpinnings as we do (having human brains), we are entitled to hypothesize similar causes to their behaviour. ${ }^{40}$ Thus we suppose that they have minds and that they are capable of inter alia understanding and desire. Concomitantly, we note similarities between their behaviour and ours, and consider whether we may be justified in supposing that a viable explanation of their behaviour is that they are related to some object in the same way we are related to some other object. We explain their behaviour by saying that they have a whim, a love, an ambition or an obsession in just those situations where our similar behaviour would be motivated by whim, love, ambition or obsession. We impute preferences only insofar as it allows us to give an explanation of others' behaviour and to predict their future behaviour. The ability to make predictions gives our hypotheses the justificatory potential due to normal empirical hypotheses; these hypotheses allow predictions and can be falsified in the normal sense. Naturally, sometimes we will use the same process

38 This overall methodology, beginning with our own introspected experience and progressing to others, on the basis of 'the legitimate rules of experimental inquiry', is essentially that offered in John Stuart Mill, Examination of Sir William Hamilton's Moral Philosophy, Collected Works of John Stuart Mill (Toronto, 1865), pp. 190-2.

39 E.g. Bertrand Russell, 'Analogy', Human Knowledge: Its Scope and Limits (London, 1948), pp. 501-5.

40 The analogy is strongest when it goes top-down from similar behaviour and bottomup from similar causes. Both strategies are effectively employed by Singer for the purpose of justifying animal rights in Peter Singer, 'All Animals Are Equal...', Writings on an Ethical Life (London, 2001), p. 37. I focus here on the top-down avenue from behaviour to preferences. An account emphasizing the bottom-up route is outlined in Jonathan Riley, Liberal Utilitarianism (Cambridge, 1988), pp. 62-6. 
of analogy to ourselves in order to impute different (i.e. non-preferencedriven) causes to their behaviour - for instance that they behaved in a particular way because of their drunkenness or habit.

On this account we do not need to have significant preferences in common with others in order to glean information on their preferences. Rather, the similarity we must have with them - the similarity that is required to justify this particular application of 'analogy to ourselves' is that their behaviour is linked to, and is caused by, their preferences in much the same way that our behaviour is linked to, and caused by, our preferences. Of course, our initial speculations about the substantive preferences undergirding their behaviour will presumably be made on the basis of those substantive preferences we think are most likely, which will naturally be informed by our own desires, hopes and dreams. However, hasty imputation of preferences formed by such prior prejudices will, if erroneous, result in incorrect predictions of future behaviour and such hypotheses may be falsified, and subsequently revised, accordingly.

Once we have basic preference-information in tow, other heuristic avenues open up. We use induction to form hypotheses about the preference-structures of people we have never met. If we think that preference $\mathrm{P}$ is likely to be highly ranked by all people, then we might immediately hypothesize that a person willing to sacrifice $\mathrm{P}$ for $\mathrm{Q}$ is likely to rank $\mathrm{Q}$ highly. ${ }^{41}$ Communication will also become a potentially rich source of information on preferences, though in different contexts we will justifiably place varying degrees of credence in personal testimony. ${ }^{42}$

Radical scepticism aside, it seems unlikely that this level of information about other's preferences should be contentious. For the bare fact that all humans, in their most quotidian activities, such as organizing a doctor's appointment or getting a pizza delivered, make multitudinous correct predictive (and often counterfactual-supporting) claims about the behaviour of many other individuals, a significant proportion of whom they have never even met before, requires explanation. An obvious explanans of these innumerable mundane correct behaviour-predictions is that humans are capable of making more or less accurate imputations of the underlying causes of such behaviour (viz. other's preferences and beliefs). ${ }^{43}$

41 Thomas M. Scanlon, 'The Moral Basis of Interpersonal Comparisons', Interpersonal Comparisons of Well-Being, ed. John Elster and John E Roemer (Cambridge, 1991), p. 36.

${ }_{42}$ For a recent overview of testimony in general, see Alvin I. Goldman, Knowledge in a Social World (Oxford, 1999), ch. 4.

${ }_{43}$ Jerry Fodor gives a trenchant elucidation of the surprising level of predictive claims necessary for everyday activities in Jerry Fodor, Psychosemantics (London, 1987), 
These various methods allow us to form hypotheses about the preference-structures of people both known and unknown. In some cases (such as in a totalitarian regime), circumstances will allow for precious little free action or free speech, and in these situations the amount of data available for imputing preferences will be severely restricted. Indeed, all our imputations of preferences in even the most ideal situations will be underdetermined by the behavioural data used as evidence for them. But this is the case with all empirical hypotheses, and we are entitled to use ordinary epistemic virtues to make inferences to the best explanation and to attach degrees of credence to those explanations, just as in all other fields. The same is true as regards our hypotheses about the mutability of preferences. In some cases we may be justified in thinking that someone's preferences may change as a result of capriciousness, maturation, external manipulation, cognitive dissonance or a 'sour grapes' mentality. ${ }^{44}$ If so, then this will affect our imputations about their probable future preference-structures, which will in turn affect our predictions about their future behaviour and our strategies to fulfil their preferences.

The question of whether these hypothesized preference-structures are intersubjectively commensurable is a subtle one, and I cannot pretend to be offering a definitive solution in what follows. However, I do wish to say enough to draw out what I take to be the fundamental link between any imputations of preferences and the implicit but necessary assumptions of commensurability. ${ }^{45} \mathrm{I}$ am not the first person to think that the consternation over how to get from an identification of preferences to an intersubjectively comparable account arises from putting the cart firmly in front of the horse. As Griffin neatly puts it, 'the answer to, "How do we get to public, intersubjective data?" may be, That's where we start. 46

Let's return to the above account of how we come to the conclusion that other people have particular preferences. We primarily do so in

pp. 3-10, q.v. David Hume, An Enquiry Concerning Human Understanding, ed. Eric Steinberg (Cambridge, 1993), pp. 55-61.

44 John Elster, 'Sour Grapes - Utilitarianism and the Genesis of Wants', Utilitarianism and Beyond, ed. Amartya Sen and Bernard Williams (Cambridge, 1982), pp. 219-38.

${ }_{45}$ Relying on empirical data and ordinary epistemic virtues, I intend to give a conceptual/metaphysical account of how people's preferences are quantified on the same unidimensional scale. In choosing this realist route (i.e. in assuming that commensurability - at least in the form germane to this issue - is discovered rather than invented) I beg some significant questions against functionalist, historicist and/or post-modern accounts of how commensurability might occur: Fred D'Agostino, Incommensurability and Commensuration (Aldershot, 2003). pp. 48-50. Note however, that even a strongly realist approach would not deny but rather augment his process of 'COMMENSURATION'.

${ }_{46}$ James Griffin, 'Against the Taste Model', Interpersonal Comparisons of Well-Being, ed. John Elster and John E. Roemer (Cambridge, 1991), p. 57. 
order to explicate some feature of their behaviour, using analogy to ourselves as a taproot hypothesis. We isolate what we consider is a relevant similarity between their behaviour and ours - perhaps a similarity in the way they work at some project or react expressively to some event. Such behaviour calls to mind the way we similarly work or react. We realize that this other person's behaviour may be explicable if it happened that she was in the same relation to $\mathrm{X}$ as we were to $\mathrm{Y}$. So we suppose that, just as we have a preference for $\mathrm{Y}$, so too she has an analogous preference for X. But note what has happened here - we do not find out the other person's preference and then try to commensurate it with our own - rather, we assume commensurability in order to posit their preference (both substance and intensity) in the first place.

I am not arguing that interpersonal comparisons are made, 'on the basis of the same sort of evidence we use for attributions of mental states generally'. ${ }^{47} \mathrm{I}$ am arguing that interpersonal comparisons the role commensurability plays in the requisite analogousness - are that basis. We are only entitled to impute preferences when to do so aids in explanatory power. Imputations of preference can only aid in explanatory power if such preferences are placed within overall theories about how preferences work within human beings and, in particular, how quantifiable strengths of preferences dictate the way they interrelate to each other and can thence be responsible for goaldirected and expressive behaviour. Our most basic evidence about such preference interrelations and their links to behaviour comes from introspection. If we assume that such interrelations between preferences and links to behaviour are the same for others as they are for us then we are entitled to impute particular preferences as an explanation of behaviour. But to make this assumption of sameness-ofrelation - if we accept that the relation is in each case quantifiable is ipso facto to presume commensurability; it means simply that all preference-strengths are being imputed upon the same scale. The assumption can be rejected, but then all aetiological significance and explanatory power dissolve, and no preferences can be justifiably attributed at all.

Once we have similarly scaled (i.e. commensurable) estimates of others' preference-structures we can estimate utilities by observing states-of-the-world to see how far these preferences are met. There is no additional subjective evaluation required at this point. ${ }^{48}$ Utilities are

47 Donald Davidson, 'Judging Interpersonal Interests', Foundations of Social Choice Theory, ed. John Elster and Aanuund Hylland (Melbourne, 1986), p. 201.

${ }^{48}$ Compare: John C Harsanyi, 'Morality and the Theory of Rational Behaviour', Utilitarianism and Beyond, ed. Amartya Sen and Bernard Williams (Cambridge, 1982), p. 50 . 
derived from an essentially mechanical process of mapping preferences onto world states. On this account, utilities are commensurable because preferences are.

Myriad objections arise to this account of commensurability - I will deal with just one. Though it may be accepted that we require significant analogousness to impute preferences, nevertheless, this 'structuralist objection' suggests, we are not quite to the point of requiring commensurability. All we need to assume is that some preference's position within someone else's overall preference-structure is homologous to some similarly ranked preference within my overall structure. A 'strong' preference merely means that a preference resides as 'high-up', relatively speaking, in your cardinal rankings as a 'strong' preference resides in mine. We do not have to make the additional assumption (which would justify commensurability) that what counts as a strong preference in your system has the same feltintensity/motivational force as a strong preference in my system.

For parsimony, let's grant that this structuralist objection does show that we do not need to make the final step to commensurability in order to justify predictions and give explanations of behaviour. But if we do have any reason to make such commensurations then the way they should be done, given the analogousness so far utilized, is pretty clear. ${ }^{49}$ To posit dissimilar scalings of preferences arising from similar causes (i.e. similar psychologies/neurophysiologies) and producing similar behaviour is ontologically profligate, and the onus of proof is on anyone who wishes to incorporate some dissimilarity to show that it is not an ad hoc inclusion. ${ }^{50}$ The gratuitousness of such an addition is particularly evident when we consider the myriad other fully commensurable attributions we justifiably and routinely make about mental life (such as estimates of intelligence, sleepiness or angriness ${ }^{51}$ ) - none of which are subject to this 'structuralist' objection.

To sum up; without assumptions about analogousness we are not entitled to impute any preferences at all, nor able to make any realworld predictions about behaviour on the basis of preferences. It is possible to argue that this analogousness need not require full-blown commensurability, but the required analogies drawn between causes and effects of preferences - and mental life in general - are enough to

49 This need for commensuration may not be a moral reason. Interpersonal commensurability occurs in bargaining and threats. See, for instance, R. Duncan Luce and Howard Raiffa, Games and Decisions (London, 1957), p. 131.

50 Allan Gibbard, 'Interpersonal Comparisons: Preference, Good, and the Intrinsic Reward of a Life', Foundations of Social Choice Theory, ed. John Elster and Aanuund Hylland (Melbourne, 1986), pp. 188-9.

${ }_{51}$ I. M. D. Little, A Critique of Welfare Economics, 2nd edn. (New York, 1957), p. 54. 
place the burden of proof firmly on someone who wishes to deny that preferences are scaled unidimensionally.

This foregoing account contends that preference and utility knowledge are not epistemologically prohibited, and that examination of individuals' choices and behaviour can lead to the formation of justifiable hypotheses on these matters. The question which now confronts us is whether the knowledge derived in this manner will be sufficient for fulfilling the demands of the three Requisite Claims. Can we claim, for instance, that individuals from liberal societies are on average at least as well off (in terms of fulfilled preferences) as people in other societies, that some consequences of our actions negligibly impact on other's lives, and that in the face of abject need, it is worth the problems inherent in taxation to provide succour?

While the foregoing analysis may serve to bolster intuitions we may have about the answers to these questions, it will not serve to persuade those who are justifiably suspect of any such intuitions (or indeed, who do not have them). While it is sometimes possible to sketch how an epistemic problem could potentially be solved, it is difficult to demonstrate that a particular heuristic method is or is not sufficient for a given end.

With this difficulty in mind, I now wish to inquire into the epistemological requirements of political systems in general as a way of resolving the issue - or at least of shifting the burden of philosophical justification. If it can be shown that almost all polities necessitate making the same sorts of knowledge-claims as those involved in the Requisite Claims then I will consider that the onus of argument is placed on those sceptics who are advancing a particular political system to demonstrate how they consider their own regimes to have access to the required information, while providing evidence that this information, and its means of acquisition, is insufficient for the utilitarian task.

Any non-anarchic political system must presume that its dictates (howsoever minimal) can be implemented. For the remainder of this section I will therefore focus on the knowledge necessary for implementation of overall polities, using deontic liberalism as a touchstone. I use deontic liberalism for two reasons. First, it is this system which is typically being propounded by critics sceptical of utilitarianism's epistemic requirements. Second, of all non-anarchic systems deontic liberalism's epistemic requirements seem prima facie comparatively minimal. By comparison, telic liberalism (where, broadly speaking, policies are aimed at creating states of affairs which maximize the autonomy of their citizenry) has considerably more onerous epistemic requirements for the formulation and implementation of policy, precisely because of this feature it shares 
with utilitarianism - the obligation to create states of affairs which maximize some moral desideratum.

While I will focus on the implementation of policies, it must be emphasized that most polities, including all forms of liberalism, have further preference/utility knowledge requirements outside of those necessary for implementation alone. For instance, deontic liberalism makes considerable use of centralized judgements of whether citizens have consented to various personal and political activities (say, whether some person consented to a particular sexual encounter) where such consent is simply a species of preference-knowledge.

Implementation is clearly a problem for the utilitarian legislator, for she cannot simply 'implement policy P', but must create a state of affairs wherein policy $\mathrm{P}$ inheres. ${ }^{52}$ Implementation requires the ability of the legislator to manipulate the citizenry in general ways, and to manipulate the bureaucracy in very specific ways. This is typically achieved - insofar as it is achieved at all - through manipulation of their utilities, by rewarding or penalizing them in different ways, by resolving the thorny difficulties involved in policing the police, and by appealing to or relying on their honesty or public-spiritedness. ${ }^{53}$ This in turn relies on the ability to know the preferences and even utilities of such individuals and make predictions about their responses to policies.

But just as the utilitarian legislator cannot simply have the government 'implement policy P' but must entrust the policy to her bureaucrats, neither can a deontic legislator simply have the government 'follow rule P', but must create a state of affairs whereby the bureaucracy behaves such that the government follows a rule or protects a liberty. In other words, the deontic legislator wishes to enact policy that will maximize the rule-following or rights-protecting behaviour of its bureaucracy (and, perhaps, its citizenry). To do so the legislator must create, evaluate and predict responses to various policies based on what it knows about the preference-structures and utilities of relevant parties. Without such data the polity has no more than nominal impact, and preference/utility scepticism becomes an argument against government simpliciter.

But if the preference-structure and utility knowledge requisite for the implementation of policies, and for the prediction and manipulation of bureaucrats and citizenry, is achievable, then it seems that in many cases the Three Requisite Claims necessary for utilitarian liberalism must also be possible. To see this more formally, note the closeness of the epistemological claims required to predict or manipulate an agent on the basis of his preferences, and those required in order to

${ }^{52}$ Gaus, 'Welfare States', p. 17.

${ }^{53}$ Elster, Nuts and Bolts, p. 158. 
make utilitarian claims about what would be best for him (as in The Compromising Claim). To predict that agent A will undertake action $\mathrm{X}$ on the basis of preference $\mathrm{P}$ in situation $\mathrm{S}$ is to say that $\mathrm{P}$ will be fulfilled to some extent by $\mathrm{X}$ and $\mathrm{P}$ is a preference that is known to be motivating to the relevant extent and all other different preferences are so constituted as to not definitively militate against $\mathrm{P}$ in $\mathrm{S}$. To say that the utility of $\mathrm{A}$ in $\mathrm{S}$ will increase by some action (of mine or someone else) $\mathrm{X}$ on the basis of their preference $\mathrm{P}$ is to say that $\mathrm{P}$ will be fulfilled to some extent by $\mathrm{X}$ and that all other different preferences of $\mathrm{A}$ are so constituted as to not definitively outweigh $\mathrm{P}$ in S. In other words, to the extent that one can make predictions about others, one is typically able to make to make utility-claims about them (though it does not follow we have the wherewithal to act on such claims, of course). Naturally, just as highly sophisticated, far-off and convoluted predictions about behaviour are speculative, so too for these types of welfare claims. But in some cases extraordinarily nuanced predictions of individuals are possible, and coarse-grained predictions about large-scale responses to policy are also possible. Again, the same follows for welfare.

This argument is not intended to show that the epistemological demands of all types of political arrangements are equal. The deontic legislator only requires preference and utility information in order to predict and manipulate, whereas the utilitarian also requires such information in order to form overall policy directives. The point is simply that the deontic liberal theorist must give some account of how this knowledge is to be collected, assimilated and verified presumably appealing to micro-, macro-, or large-scale socio-political observations - and then show clearly why this fact-finding methodology will not suffice for the utilitarian's further requirements. Moreover, recalling from $\S 1$ the distinction between 'right' and 'rational' action, in excogitating the utilitarian's requirements we must be careful not to slide from the arguably correct claim that the utilitarian has an infinite thirst for more information, to the erroneous belief that the utilitarian has a requirement of infinite knowledge. Depending upon the degree of data-agreement, acquired knowledge may very quickly justify movement from our toolbox of social science mechanisms to the utilitarian recommendation of broad political trajectories.

There is also one way in which the utilitarian legislator may find herself on firmer epistemic ground than her non-utilitarian counterpart. While both polities require data on preference-structures, the utilitarian legislator may be comparatively better-placed to collect the data she requires. It is well-known that merely because data on some group of people's preferences will be used by a centralized agency to inform policy aimed at furthering their aggregated preferences, it does not follow that any individual in the group will be motivated 
to provide accurate preference-data. ${ }^{54}$ Numerous cases arise in which an agent can gain by strategically misrepresenting her preferences. However, this verity of social science should not obscure the loose but nevertheless important correlation between the desire of the individual giving the data (to have her preferences paid at least their due consideration) and the mandate of the utilitarian institution receiving it (to pay their preferences due consideration). Contrariwise, for polities that are not motivated to produce the maximum fulfilment of the citizen's preferences, there is considerably less correlation. As we saw above, non-utilitarian legislators require preference knowledge for the successful prediction and manipulation of their citizenry and bureaucracy. It is a wide-open question whether or not any particular person stands to gain from supplying information pertinent to his own subsequent prediction and manipulation. In non-utilitarian polities therefore, preference-knowledge may be harder to come by, for the correlation between the goals of the individual and the mandate of the centralized institution has been significantly diminished. This may mean that in such arrangements even very loose claims (e.g. 'that most of the time most citizens will not be advantaged by radical misrepresentation of their preferences') cannot be substantiated.

\section{CONCLUSION}

I have argued that the sceptical case against the utilitarian has not been made. I ceded that in addition to the rough and ready claims of social science, the utilitarian does need to access reliable information about people's preference-structures and utilities. However, I adduced two arguments contending that this information was within reach. First, I put forward a conceptual 'how-possibly' account of the availability of such information, drawing on the lynchpin of analogywith-oneself. Second, in the manner of the tu quoque demand for consistency commonly brought to bear against selectively deployed scepticism, I argued that the deontic liberal also requires this type of information. To make the sceptical argument persuasive the deontic liberal must show through what methods the knowledge-claims requisite for his own political recommendations are possible, and then demonstrate why the epistemic threshold occurs before the utilitarian has sufficient information to fulfil the Requisite Claims. While I have phrased this last point in terms of illustrating a level of equivalence between the epistemic requirements of utilitarian liberalism and other polities, a similar argument could be drawn for equivalence between

54 John Elster, Solomonic Judgements: Studies in the Limits of Rationality (New York, 1989), p. 179. 
the informational requirements of utilitarian liberalism and the requirements of personal goal-directed action as ordinarily conceived, with its clear requirements of preference-knowledge for, inter alia, the prediction and manipulation of other persons.

My project has its limitations. Most significantly, I have only argued that we have reason to believe information may be available to justify the utilitarian in making the Requisite Claims, and so can be in a position to recommend some polity or other to a specified populace. The argument establishes that empirical facts are available that may well decide the issue. However, I have not tabled any empirical facts that suggest that answers to the Requisite Claims would militate towards liberalism in particular. Perusal of the postulates is enough to suggest that liberalism will be one of the polities that the utilitarian will be very interested in, but it remains open to empirical data whether the Requisite Claims actually reject or accept this polity in the case of any given group of people in their particular circumstances.

That said, it is my deep suspicion - and what follows here is little more than hand-waving - that it takes very little fine-grained empirical data to justify the utilitarian in deciding that liberalism is likely to be the best strategy in the vast majority of contexts. On all levels, the micro-, macro- and large-scale, there is good reason to assert the clear ascendency of the liberal polity over significant periods of time and diverse milieus.

On the micro-level, it might be noted that once civil rights and a free-market are established, a wide variety of preferences that can be fulfilled by unilateral action and bilateral exchange are potentially able to be compossibly fulfilled. Civil rights and the free-market are tools that allow the fulfilment of a large, varied, changing multitude of preferences, including many we may not even have imagined. But this is not the case with public goods; each specific public good to be instantiated requires specific legislation enacted for that particular public good - legislation that does not ordinarily aid in the provision of other public goods. This specificity makes such legislation potentially much more reliant on correct and fine-grained preference-information, and also much more rigid and inflexible. Unless we have evidence that there is powerful conformity of specific preferences across populations over lengthy periods of time, it becomes increasingly likely that the devolving of decisions to individuals allowed by liberalism will more expeditiously cater for the fulfilment of people's diverse and dynamic preferences.

On the macro-level, the ability of liberal polities to provide significant levels of each of the proffered 'primary goods' becomes important empirical evidence does not imply that one or two primary goods are lexically preferable to the others, which would be required for the 
utilitarian recommendation of certain other political arrangements. On this level too the value of free speech becomes evident - the greater the allowed liberty of action and speech, the more preference-data becomes available to the utilitarian legislator. I have just noted the problems with the specificity and rigidity of public-goods legislation and institutions. If these institutions are not being continuously informed by reliable knowledge of people's preferences (as evinced through freespeech, market-choices or democratic mechanisms), then there arises the grave danger of - if not outright corruption and distortion - the ossification or, even worse, an unwanted and unnoticeable drift in the effects of such entrenched institutions. The productivity of the freemarket system is also important here: both in generally improving prosperity and also in allowing, through the mechanism of taxation, comparatively large amounts of resource to be redistributed in various ways. We might also note that the strength of egalitarian gains occurs most stridently when people are in the most destitute and dependent states. If either the free market, or state education and training, or direct welfare, can keep people out of these lowest states, then we might incline towards the conclusion that - beyond this - egalitarian redistributions rapidly lose their attractiveness.

On the overall level a wide swath of data becomes apposite: a lack of famines and civil wars, greater stability and transparency of governments, the availability of welfare for the poor and of public education systems, generally higher living standards, greater social mobility, greater opportunities for women and minority groups, the tendency for people outside of liberal societies to wish to emigrate to them, and not vice versa, and so forth. Once this sort of data is accepted as admissible evidence about utilities and preference-structures - and such has been the thrust of this article - then I suggest that the utilitarian recommendation of liberalism will be swift and decisive.

\section{APPENDIX: THE EGALITARIAN POSTULATE}

The egalitarian postulate: humans fulfil their preferences by applying resource with diminishing marginal returns. If we know nothing further about which particular agents have the more (or less) efficient resource-to-utility conversion functions, then a totally egalitarian distribution must be the rational choice - i.e. the option which will maximize expected utility.

The egalitarian postulate is just one of the myriad ways in which the notion of Diminishing Marginal Returns (DMR) infects utilitarian concerns about distribution. On the broadest rendering, the distributive concerns of the utilitarian are essentially those articulated by, for example, Peter Singer in his arguments for aid for developing 
countries. ${ }^{55}$ The egalitarian postulate is merely one way of expressing a very particular application of these general concerns. As noted earlier, however, the postulate is by no means the typical way of rendering these concerns, and differs most pointedly in its application even in situations where two individuals' resource-to-utility conversion functions may be radically different (subject to their both obeying DMR).

The above formulation of the egalitarian postulate has one particular feature relevant to my agenda: the postulate works without any claims about which individual has which type of resource-to-utility conversion function - indeed, it must be forthrightly emphasized, this postulate relies on such ignorance in order to be applicable (see illustration below). The reason this feature is germane is because it is occasionally claimed that arguments for welfarism rely on more knowledge than is possible, and that in the putative situations of extreme ignorance that agents, legislators and centralized institutions actually face, utilitarianism will - because of this general lack of information imply liberalism. The quite specific point of this rendering of the egalitarian postulate is to show that utilitarian arguments can be given for egalitarianism even in situations of massively attenuated knowledge.

To illustrate the egalitarian postulate, let's consider its use in the simplest case. Suppose we have two agents, $\delta$ and $\phi$. Suppose (as per the stipulations in the egalitarian postulate) that we have no individuating data which makes us believe that one of them is more liable to have a particular type of resource-to-utility conversion function than the other. But given our access to general social science tenets we might have a general belief about any given agent that she has a (say) $p$ probability $(0 \leq \mathrm{p} \leq 1)$ of having function $A$ and $a(1-p)$ probability of having some other function B. These functions A and B may be radically different in many ways, but they both obey DMR. This is just to say that with each additional quantum of invested resource to any A- or B-type person, we can expect a lower return (of utility-increase) than we procured with the last quantum invested with that person, or more formally that for any function $Q$ which obeys DMR, $Q(n+1)-Q(n)>Q(n+2)-Q(n+1)$. Suppose further that agent $\delta$ has $\$ \mathrm{n}+1$ and agent $\phi$ has just $\$ \mathrm{n}$. The egalitarian postulate claims that, for any $\mathrm{p}, \mathrm{A}$, and $\mathrm{B}$, it will maximize expected utility (E.U.) to invest the next dollar with $\phi$ and not $\delta$. Is this true?

Because of our lack of individuating data, we find that the function we apply to our expected utility calculations for both $\delta$ and $\phi$ is the

55 Peter Singer, 'Famine, Affluence and Morality', Philosophy and Public Affairs 1 (1972), pp. 229-43. 
same; that is, E.U. $=p A+(1-p) B$. Call this ubiquitous function ' $Z$ '. Given that functions A and B both obey DMR, this function $\mathrm{Z}$ must also obey DMR. Now it merely remains to be seen that the expected utility of the egalitarian arrangement is higher than the expected utility of the unegalitarian arrangement, i.e. that $2 \mathrm{Z}(\mathrm{n}+1)>\mathrm{Z}(\mathrm{n})+\mathrm{Z}(\mathrm{n}+2)$.

But we know that $\mathrm{Z}(\mathrm{n}+1)-\mathrm{Z}(\mathrm{n})>\mathrm{Z}(\mathrm{n}+2)-\mathrm{Z}(\mathrm{n}+1)-$ because this is just what is required by $\mathrm{Z}$ obeying $\mathrm{DMR}$ (as per the above stipulations). The simple addition of $Z(n+1)+Z(n)$ to both sides yields the desired equation.

The above holds true across the obvious variations - an increase in population, and any additional numbers of candidate resource-toutility conversion functions, with any given probabilities (assuming they sum to 1 ). Note once again that the important condition is that the legislator does not have individuating information about the citizens. It is worth observing, however, that even when the legislator does have individuating information about one group within a population (e.g. everyone within this population-subgroup is comparatively more like to have A-type functions), the egalitarian postulate will still hold within that subgroup. ${ }^{56}$

h.breakey@uq.edu.au

${ }^{56}$ This article has benefited from critiques of earlier drafts by Julian Lamont and Gerald Gaus. 